\title{
The body and the intellectual
}

Gregory Sporton, University of Greenwich

In February 1986, I was a young professional dancer at the start of what would become a modest performing career. I had recently graduated from an excellent school where I took too little notice of what I was being taught, but the school's ambition and aspiration certainly impressed itself upon me, as it would for the rest of my sojourn as a dancer. I was eventually offered a job with a small dance company in New Zealand, based in Wellington. Without much thought, I took the short plane journey across the Tasman from Australia and got going.

The company had an eclectic repertoire (it did lots of schools' work requiring accessible dances) and some fine dancers. It lacked programmable length works, and when the director turned to me to ask if I could contribute something, I was not shy about doing so. I made four dances with the company during that year, and this is the story of one of them. It is also a discussion about what we can learn from dance as a practice that challenges the notion of it as an intellectual project, and what satisfactions we are seeking from it when we either do it or watch it. Thus, a young, 21-year-old choreographer embarked on making a short, ten-minute-long duet with an accomplished, if only slightly older, dancer who could match him for strength and presence (which in such times I had thought I had in spades). The dance was performed many times in the company's repertoire as we toured the length and breadth of New Zealand during that year, well received and well-reviewed in the local newspapers.

It was an experience that both of us would forget for more than 30 years, until an opportunity arose to revisit its delightful structures, but more on that below. The purpose of reviving it as a project was unstated and rather amorphous to begin with, but I anticipated there were bound to be plenty of spin-offs. I had not, at that point, imagined this essay to be one of them, at least not the direction this essay will take. I expected some reflection on the process, and an appreciation of the passage of time as it stretches behind me, a personal identity defined through change, a creative challenge to reinterpret. But, as is often the case in creative practice, I found a far more interesting set of problems kept interrupting the process. 
Despite my first career as a dancer and my second one as an academic, I find myself with little sympathy for the cottage industry of contemporary dance, especially its manifestations in the United Kingdom. Having once been a culturally powerful force (in the 1980s), it subsequently descended into an art form for losers, a consolation prize for the dispossessed and disaffected, watched by few and indulged in by those seeking self-validation or therapy through it rather than making serious artistic statements; at least this is how it has seemed to me in watching its progress in the United Kingdom over the past twenty years. That these wounds were self-inflicted, and colluded with by an academic caste that shared its failure, both in terms of their own dancing backgrounds and the lack of penetration of their ideas outside the narrow confines of dance studies, simply sharpened my criticism of it. The contribution of dance academia to contemporary danceis pockmarked by self-pity and selfcongratulation, and a selective appreciation (all movement is dance, but some is reviled on political grounds: either too sexual, like pole dancing, or too powerful in reinforcing an image, like ballet). There has been a marked preference for work that reinforces the sense of political superiority that comes with being within the university. Dance academics are all too enthusiastic about enjoying their status as establishment-based supporters of a needy community that they can claim to be a part of without being subjected to its hardships. The inadequacies of their analyses have always seemed marbled by negative interpretations, a fear of the body rather than a celebration of it. The triviality of their activities has not seemed to me worth challenging for many years. This would still pertain, but for the experience of dancing that I alluded to above. A long gap in my association with it has me returning to it with both a detached attitude and an awareness of its limitations. Moreover, while the proposition of dance as an intellectual project has always seemed to lack a foundation, the usefulness of it as a practice in challenging ideas has been duly overlooked in a fumble of self-justification about being repelled and seduced at the same time. This, in itself, is an important clue to the mistaken efforts of its intellectual accounts. Such plangent remarks require some explanation, and I am obliged to the process of revisiting a dance after such a long period of time for the means to makeone.

Dancers generally are puzzled (and marginalized) by one of the key cultural premises of western civilization. They struggle to conform to it in their everyday existence, but the persistence of this idea in culture generally makes them outsiders to that culture, and explains their appearance on the periphery of society. The insistence that the wider cultural assumptions applying to the body must apply to them is the theme of this essay. Dancers are not alone in experiencing this bewilderment: they are merely the group I know best who suffer a fundamental misunderstanding of their experience and often have it played pack to them by academics in shapes 
and narratives that they do not recognize. I recall, for instance, giving a group of dancers from a well-known ballet company an essay comparing ballerinas to phalluses. They were outraged. But given the absence of a direct voice that goes with most dance, dancers are more prone, vulnerable even, to having their experience explained, talked about in their own presence as if in the third person, than other groups experiencing something similar. There are barriers to engaging and refuting a fanciful interpretation, and they include a well-known disregard for academic accounts of what they do.

It is not that this phenomenon has gone unnoticed (I have used the word deliberately): it definitely has not as I will show presently. There have been a number of onlookers interested in identifying it, but the prism through which dance as a body practice is viewed refracts the dancer's reality into a spectrum limited by the culture of which they are meant to be a part. The very identification of a problem in this regard demands reconfiguration of phenomena into the comprehensible, and it is the habit of doing so against a particular intellectual tradition that I am seeking to challenge here. The interpretation is often wilful, predetermined and distorted by engagement with a practice at odds with its interlocutors, and requires some better answers than the ones we have now, the escape into phenomenology, for instance, as a get-out clause to explain away the difficult moment where explanations are superfluous.

It starts with Descartes. He began his project in pursuit of an explanation about existence, inspired by the geometry at which he was so adept. He started off as a younger man with the challenging idea that our fate (our certain death) was determined by our imagination or lack thereof, that we died because we had the expectation of doing so. His early speculations on this matter are often dismissed, though to me it seems this particular idea led him to the one for which he is most famous: Cartesian dualism, or the mind-body problem, the Cogito, 'I think, therefore I am'. Ever since, this aphorism has privileged the intellectual over the body, implied (though Descartes might be horrified at some of the applications of his ideas) that the formulation of existence and experience ought to be the preserve of the mind. Intellectual conception was the only guarantee of a truthful assertion, the very capacity for formation of the proposition is what makes the proposition true. In itself, it becomes an extension of much older ideas in intellectual culture, about the unobserved life not worth living, for instance (attributed to Socrates and that comes to us via Plato), or the agonies of Augustine: 'Give me chastity and continence, but not yet'. In themselves they sum up the dilemma of the intellectual when faced with the realities of the body: in all cases, their solution has been to separate the physical from the rest of their existence, 
ordering matters as required by the intellect, assuming that the power to propose is equal to the power to exist. This is a very interesting thought, and one that inspires the 'noospherians', those who think our future will be in uploading ourselves into some kind of cosmic Internet and relieving ourselves of the exigencies of the body in doing so. I suspect that were this even possible one day, the permanent deferral of death might result in some exceptional procrastination.

It is worth briefly examining Descartes' reductionist and solipsistic account as it stands in both the Meditations and the Principles to see his limited view of the body. He views the body chiefly in terms that he finds unreliable and therefore not consistent with the higher truths of the mind that he most frequently expresses in analogies that reflect the geometry that he trusts as objective reality. The notion of hunger or the experience of pleasure is as disconcerting to Descartes as the presence of emotion, and equally unreliable as a source of confirmation of self or of the existence of God, which were the main aims of the texts. The perfection and simplicity of geometry is assumed as an absolute, in circular arguments that extrapolate this notion into the certainty that 'the mind ought to conclude clearly that a supremely perfect being exists from the fact alone that necessary and eternal existence is included in the idea of a perfect being' (Descartes 2003: 117). The very method he employs predetermines the outcome of his enquiry, which is not an investigation but a justification of his personal need for both a God and a God that approves of reductive reasoning. This looks like his preferred means of understanding: mathematics. His fear of the body is linked to a fear of imagination, the third point of a triangle of dynamics that represents, for Descartes, a great source of deception. His dismissal of it despite allowing its power over thinking ('I know that none of those things that I can understand with the help of the imagination is relevant to what I know of myself' [Descartes 2003: 26]) is based in his assessment of it as a distraction to a mind that likes to wander and is 'not yet willing to stay within the boundaries of truth' (2003: 27). His account of the body as a separate entity to the mind is based on a dissatisfaction with the arrangements of nature that places his mind at the body's mercy, requiring a reversal of its instincts to enable efforts at conceptualizing. In arguing up of the management of the body by the brain, Descartes commits his concept of perception as belonging entirely to the mind, despite acknowledging the instinctive or the sensual as not requiring intellectual interventions. It is 'some kind of machine made from bones, nerves, muscles, veins, blood and skin $[\ldots]$ ' followed by an account that places the mind at the end of a chain that may start anywhere but always finishes with the mind (2003: 66-68). Nowhere does he extend to the body a level of agency of its own, even where it operates in response to external stimuli without the intervention of the will. Even this concession 
in itself would simply enhance dualism rather than resolve his fear that the body and the imagination might prove to be more powerful as forces of existence than being 'a thinking thing' $(2003 ; 26)$. What the Meditations and the Principles show us is that Descartes neither understood nor trusted his body, nor his imagination, and given he had spent much time denying both while preferring to conceptualize means he is not a remotely reliable source on this matter. The capacity of the body to exist as a unified entity is dismissed as a proposition because even though he 'cannot distinguish any parts in myself: instead I understand myself to be a completely unified and integrated thing' (2003: 67); it is the reductionism that guides his thinking in general, which he transfers to the body. Claiming the loss of parts of the body does not entail corresponding loss to the mind produces a selective and partial conclusion predicated on both the specific example of limbs (why not organs?) and an underestimation of the impact of such a trauma. What is entirely lacking in Descartes' account of the body is its potential as an entity of expression, especially of expression of the imagination. This is the work that dancers do with no less dedication than Descartes' pursuit of conceptual perfection through geometry, but there is no room for it. He is a 'thinking thing'. His body is merely responsive to that thinking, plagued with illness or discomfort and sometimes fooled by pleasure.

Giambattista Vico, a less well-known philosopher of knowledge and a contemporary of Descartes, found this quite antithetical in his concept of knowing. He founded his ideas about on memory or imagination, on how the cultural determined the philosophical and defined the rational. While locating knowing in the realm of the mind, he acknowledged the possibility that to get there might take participation in an activity that produces qualitative outcomes: this is the realm not of the creative but of the critical intellectual. His withering observation that 'we demonstrate mathematics, because we create their truth' dismisses Descartes' efforts to claim them as objective reality and proof of the existence of the creator. Descartes' conclusions, like Vico's or mine, are therefore cultural rather than absolute. Descartes argued for such absolute concepts to claim their application to all periods and societies. Vico, by contrast, 'was led to investigate in all their profound divergencies and contradictions the modes of feeling and thought proper to various times' (Croce 1910: 45). Of course, this led to the very opposite of the abstract, to the sensual and bodily as the core of an existence that makes no distinction between thought and life, but accepts their interrelation as the mode of being.

To explain why this is significant, I might start at the obvious limitation of seeking understanding through a life already divided between the comforts of intellectuality and the realities of physicality as a contingent process. 
Quite simply, even the mode in which the intellectual engages with the body requires more than the limited expressive power of thinking. Dance reveals this problem very well, noting that it is not intellectual process by other means. Intellectual inquiry in other art forms invariably acknowledges this truth: if it could be formulated in words, then it requires no art. However, in much of the rest of the arts the emphasis is on what is produced rather than how (I think especially of music and the complexities of the how, which often remain unremarked upon despite the dependence of the end on the means). Dance depends on a body to represent it, and the movement of the synapses is an inadequate substitution. In fact, it is no substitution at all, and a dance of the thoughts is a metaphor. The hubris demanded for offering an account of the body by someone of such limited experience of it, and whose method of development of the concept is desk-bound, seems remarkable. A clear preference for the life of the mind cannot possibly be the basis of an authoritative account of the body even if, as intellectuals are want to do, you accept Cartesian dualism as the basis of existence and the only possible point of departure. I will return to this later, noting that some of those I am about to disparage have at least glimpsed the foothills of this problem, but they have dealt with it in an entirely intellectual way, while making claim to speak for the physical. This does not even make sense in Cartesian terms. It turns out that minds and ideas can evolve, but bodies do not: the body referred to in the abstract is always the same body, and that body is only ever a concept, despite increases in our understanding about how it is constructed and improvements in technique. The ideas have a life of their own that is happily denied the very vessel of the existence they think they are experiencing or explaining.

I suspect this general privileging of the mind is why dancers see themselves outside of society and often have problems associating outside their own closed circles of social experience. Many years ago, when I was first looking at the literature around intellectual enquiry into dance, I repeatedly found the irreconcilable propositions of dance, as innate to human experience on the one hand and dance as a marginalized cultural practice on the other, repeated in the impenetrable and serial bungling of dance academics. They were seeking to express the difficulties of holding the two contradictory propositions simultaneously, without the insight or intellectual heft to make such propositions stick. This was not their only problem: dance was cited as both an expression of primitive urges and a construct of culture; dancers were both horribly brutalized and symbols of freedom; choreographers were the last word in authorship but dancers could not be distinguished, Yeats' style, from the substance of the dance. The examples are many, and the damning conclusion that one comes to is that, as yet, no seriously intelligent person has ever thought deeply enough about dance to give it an intellectual framework that 
has stuck. I acknowledge the contributions of some tremendous reviewers like Arlene Croce or Edwin Denby, some cultural specialists like Kirstein or more latterly Mark Franko, historians like the ever meticulous Slonimsky or Holman, but dance still waits, will go on waiting for its Gombrich or Panofsky to give it its theory, or for a Brecht, Stanislavsky or Augusto Boal as master maker/thinkers, or an Adorno who could make claim to complex understanding of culture and economics as a whole through being beautifully trained in both music and musical composition. Laura Mulvey is first and foremost a filmmaker. Even digital technology has Jaron Lanier. For dance, this will never happen, and the why requires an explanation.

In the absence of such groundwork, those who have thought about dance have resorted to the authority of those who have thought about the body. There have, indeed, been a plethora of them, especially in the late twentieth century, and the names of Foucault, Merleau-Ponty or Deleuze and Guattari feature heavily in intellectual accounts of the body as it engages with dance. The limitations of such thinkers on the body have been pointed out many times: their inability to escape the legacy of Cartesian dualism left them confecting ever more unlikely realities about it. These, like the Social Constructivist thinking emerging from Foucault's work, for instance, discredit them as having little more than a passing interest in the body except as it could be proposed as an extension of social forces (thus managing, in a moment of supposed insight and reordering of priorities, to reduce the body to its previous invisibility). The alternative has been the psychological imperative. As Heidegger jibed about Sartre, Ricoeur and others, 'The French psychologists also misinterpret everything as an expression of something interior instead of seeing the phenomenon of the body in the context by which men are in relationship to each other'. We are, really, in a dance with the rest of society, and we are not the choreographer. Merleau-Ponty's notion of the phenomenological restricts investigation of bodily experience to that which can be described. This limitation turns his propositions into something akin to Schrodinger's cat, the inexpressible is proposed as unknowable. Should the knowledge of dance, in Vico's sense of something experienced, imagined and remembered, be as impossible as all that?

Being beguiled by continental philosophy might not prove much of a starting point for an understanding of dance and its challenging manifestations. The extension of enquiry into spectatorship, using borrowed ideas from the cinema, is equally problematic. Mutatis mutandis, the exercise only results in reinforcing some conventional identity politics: the male gaze apparently dominating an art form where not only are most of the performers female, but most of the audience are as well. Rather than dig out the complexities that might make it 
so, and make it sufficiently popular so that academics may make a career from observing it, I am repeatedly shocked at the extent to which the gauze of a predetermined view is applied to the phenomenon in front of it, using the gaze as a pretext. This is rarely argued but often asserted: an example;

My attention was frequently diverted from the choreography to the presentation of 'perfect' bodies with outstanding skills. I watched in the hope that I might be able to transfer that skill to myself. I frequently left performances transformed not so much by the communication of the choreographer's vision but by the feeding of my desire's dream for a 'perfect' body. This is part of the cruelty of dance in an oppressive society. (Adair 1992:79).

writes one, determined not to be seduced by the charms of the performance by the force of the non-sequitur. Quite a lot of baggage being taken into the theatre there, I suspect. Projection onto the action of sexual preference is disguised by apparent enquiry into the ambiguous role of the male in dance, especially western dance and especially ballet. Yet this seems to belong to a distant era of intolerance and prejudice, distracting from what other qualities might be available to an astute observer not expressly seeking a reinforcement of their personal convictions or life-choices. Notwithstanding the poor quality of this activity as intellectual enquiry, it seems difficult to hope for much insight from such lightweight critical approaches. What then is the responsibility of the intellectual in formulating a notion about the body?

In the first place, it might be useful to identify some of the prejudices being displayed. The first, and most important to acknowledge, is the profound and unshakeable belief that enquiry of this sort could leave us with a comprehensive understanding about the phenomena in the first place, noting its story would be, by virtue of Descartes, that of the mind drawn to take bodily action rather than of a holistic phenomenon. In other words, such enterprises are doomed from the start, given the unsuitability of the material to the method and the experience of the enquirer. It is time to humbly express the limitations of the intellectual when giving an account of experience that is fundamentally discordant with their world-view. At best, it is partial in two senses of the word. It has a home-team bias, dealing with such matters as attract intellectual interpretation, and it can only deal with a fraction of the whole. This suggests I have an idea about recasting the role of the intellectual in this context, and I certainly do. 
The real opportunity to understand the body looks more like Vico than Foucault. To quote Isaiah Berlin, 'Vico’s central point is that poetic feeling which must 'plunge deep into particulars', cannot exist when people think in concepts'. For Vico, inspired singers (and to Vico, Homer's voice is the great example) cannot coexist with philosophers and do not need to. As Croce later observed of Vico's treatment of him, to Vico 'Homer was a great poet precisely because he was not a philosopher. He had a retentive memory, a strong imagination and a sublime mind' (1910: 191). The means of being expressive was by avoiding philosophy altogether. This meant a creative construct of characters, similes, images and comparisons that would not affix itself to an intellectual project, and in its time (the dawn of the Age of Enlightenment) Vico's arguments wrested the interpretation of ancient texts from scholarly imposition. This approach did not (and does not) preclude appreciation: it changed the context of it into one that seeks to understand the origins of its power, and to accept a context where the critical intellect is inevitably accompanied by the loss of imaginative force. Dance helps us because it sets us outside the intellectual in our response. Mallarmé, the symbolist poet, was wrong when saying of Loïe Fuller that she was 'writing with her body'. She was doing nothing of the sort: she was dancing and he was writing about her. Indeed, the story of Mallarmé's riposte to Degas, when the painter was complaining about not being able to write poetry despite being full of ideas, is instructive about the force and substance of art-making. 'Poems are not made of ideas. They are made of words.' The symbiotic relationship between the dancer and the dance that Yeats spoke of was perhaps closest to an analysis of the problem that we have yet seen, and this coupling precludes the intercession of the intellect.

I want to speak briefly then about the process of dancing, something that I have done very little of for the past fifteen years prior to this project. An explanation is required of why I have returned to the subject with such vehemence, and claiming an unlikely reconnection with its practice. It arose from receiving an e-mail in 2015 , when the small dance company I once worked for decided to have a reunion for its thirtieth anniversary, during which time it had evolved into a significant contributor to New Zealand's dance culture. They turned to the same dancer with whom I worked 30 years ago to organize the event. The questions were simple: could I attend (no, too far at such short notice), but also, did I have any clippings or photos from that time? It turns out they had nothing from the period. Once contacted, I rifled through the few relics I have of my performing career. There is not much, considering the international context of it, and the fact that dancers are not paid enough to carry a personal archive around with them. Despite the great gaps of distance and time, I discovered to my surprise that I had a collection of videos that I myself barely recalled were in my possession. Once the tech team 
at my work had transferred them to digital, I published them on Vimeo and sent the links. But it was hard to resist the simple beauty of our duet, danced to nostalgic music hall songs, and I e-mailed them to that effect. The performance of a fractious relationship set to sentimental music from long forgotten operettas by some beautiful young people seemed evidence of something worth following up. I sent the video back to New Zealand with the warning that it looked good enough to revisit, but I was not especially serious. It was only when, looking at the freshness of the choreography and the weight of its themes, it occurred to the organizer of the reunion that while a reconstruction could (and should) be ruled out, there might still be another dance waiting for us inside this one. After all, the original young performers had their lives ahead of them, while we now had enough life to understand the vagaries of love and to have experienced its joys and sorrows.

Through a long process of mutual coaxing, concerns about finances and our mutually aged bodies with their various legacies, we agreed to rework the dance in a performance at the University of Greenwich where I now head a creative practice department. This required some extensive rehearsal and our performance was always planned to be interpolated with the videos of us as younger people. We were not about to reprise the original, but to make a different one out of the remains of the first. For the performance, our audience was not going to see a dance from 30 years prior performed by the same people who did it so long ago. Neither myself nor Sandra Norman, my partner in the original, could make much of a claim to being or doing what we were then.

The very prospect of it, once it came to us to commit ourselves, had some bittersweet memories for both of us: we were never particularly close, and we had both been very focused, ambitious young dancers. But (essential to this project and critical to my argument) people change. Our destinies as dancers and as people continued beyond the shadows that still existed in faded VHS tapes from the past. The contrast of us in the presence with the couple from the past proved not only theatrically irresistible; it brought about a daily encounter with past that was emotional as well as physical, and produced a rather brave and moving result.

I remain grateful to Sandra for making the journey to the United Kingdom and enduring three weeks of rehearsals, as we both nursed our long-standing wounds from performance careers while seeking something new from the dance. There are two main observations to be shared about this. For an art form that all too often appears to celebrate youth and vitality, it is worth understanding and observing the passage of the body through a succession of states. The body is wildly unstable and the dancing happens within a framework of 
circumstances, one of which is the unreliability of the body and our memory of it through time. As Foucault noted, it is important to be clear in the history of ideas about whom you are speaking. The big question he raises in discussions about Marxism is which Marx we might now be talking about, given the variation in his thinking across a long period of time. It matters. If this is true for the process of ideas, noting this is usually only linear in retrospect, it is an almost unavoidable truth for two dancers who last performed this work (or a version of it) 31 years ago. The weight of time contrasts the physical challenges of today with the ease of the past, but it also lays bare the lightness of our earlier lives and the complications of our present ones. Our destinies are not simply physical ones, but are about how we have moved along with time in all the aspects of our human experience. This was expressly a theme of this performance: it was not about trying to relive the past or an inability to put that past behind us. Rather, it has been an opportunity to revisit the theme of the earlier dance and ask how the passage of ourselves through time might enrich a precocious work performed by people with, at that stage, nearly all their adult lives ahead of them.

I have suggested earlier that intellectuals think they are the only ones with a franchise on the validity of ideas because the manifestations of dance seem to look just the way they always did, that the absence of a direct voice in its presentation gives scope for interpretation that is often exploited. That indicates how little attention they are paying to the phenomenon in front of them. Most choreographers, and all dancers, understand how fragile those manifestations are. They are fundamentally contingent. Without wishing to be drawn further into the failings of the history of intellectual enquiry into dance, one of the others is the preoccupation with positing dances as text (hence my reference to Mallarmé earlier). Most published, written texts demonstrate some sort of stability, and writers and editors worry over them given the permanence and authority of the printed word. A new edition or translation cannot alter the substance of a work and still be thought of as the same. In dance performance, this is not entirely true: dances are far more prone to dynamic change, and become rather moribund once strictly formulated. What is true is that rehearsal will build up particular habits of going about producing a performance, but, as the proverb says, you never step into the same river twice. That is the reality of performing a dance.

The rehearsal process was full of surprises for us. After all, we had not even met for 30 years in the first place. But it was remarkable how quickly we resumed some old patterns. Some parts of the dance were easy enough to learn again; indeed, where we got some sections wrong our bodies and their deepest memories were often the 
most reliable guides to setting ourselves straight or demanding an adaptation. Sandra is still full of advice about how I might be a better partner, and I still listen tolerantly, and begrudgingly adapt. For Sandra, dance has shaped her life in a stronger way than it has mine, and this raises questions about dance as a culture and its impact on individuals. While feeling my dance experience determined some of my critical character features (self-discipline and self-denial being two of the most obvious), in Sandra it is evident to see her features and her existence as a dancer are symbiotic. She is permanently imbued with notions of performance about which I am merely nostalgic. We both recall the performances where the videos we worked from were made: we had a fight before one of them, and before another we were so cool about performing this within a very long programme that we thought of it as a rest along the way. By that stage we were engaged in the best mode of performing any dance, the one where the dance does itself through you. This takes tremendous focus, and I suspect it is no different to professional athletes or musicians. The dancer works towards a point where they are able to find a place where thinking is unnecessary and even distracting, that, no matter what exertions are demanded, you perform through the dance, you become it and that defies intellectual process. It is not the steps but the means of inhabiting them.

I am reminded by the way one prominent dance academic dismisses this idea. 'Dancers', she says, 'describe this experience as the body taking over, as the body thinking its own thoughts [...] but this is as inaccurate as it is unhelpful; it is merely the inverse, again, of the pen-pushing body' (Foster 1995: 10), a phrase that seems to know nothing of Heidegger's observations on the 'essential realm of the hand' (1982: 81). She is obliquely suggesting the intellectual limitations of dancers, who seem to her too inarticulate to give her the answer that she wants: an explanation that fits her world-view of dancers, especially ballet dancers, as manipulated yet powerful, a typical paradox of the dance academic who sees Foucaultian power structures everywhere but cannot help acknowledging their transcendence by the actions of a well-trained dancer just doing their job onstage. Being so distracted she has missed a quintessential reality of the dancer's experience, and missed altogether Heidegger's insightful comments on the craft practice of writing. Both are entirely the reverse of being inarticulate, if I may play a little game with words, as the joints and sinews create through action something defying conversion into text. These are the conditions where the dancer does their best work. It is not an act of stupidity, but of balance: ignoring the focus on the head into the whole corporeal experience and allowing the performance to happen. When Sandra Norman says to me in rehearsals that 'you can't think and breathe at the same time', I understand exactly what she is saying: there is a performance state that requires 
proper focus on how the whole of the dance manifests, and interrupting this with commentary distorts and disfigures the intent. In the process of remaking the work I have found myself wanting in this regard. All too often my long-standing retirement from the stage does not reveal itself in rehearsal as rusty virtuosity, rather it has shown me an inability to connect my physicality to the doing of a dance. This is not a function of age, but the lack of a certain kind of focus that encompasses being. I simply no longer have the intensity and singlepurposedness required to give justice to the full demands made by the dancing in the way I was happy to give decades ago. I sense my disconnection from that state of grace that dancers seek, of allowing the dance to unfold itself. My technical shortcomings that translate into incompetence are the result of a long period lived in the pursuit of goals beyond a great performance. You cannot just step back into the river.

This sobering thought brings me back to my earlier promise to explain why dance and its intellectuals can never be reconciled. There is a gulf of mutual incomprehensibility that goes beyond Cartesian dualism: after all, only one side is buying into the idea and is explaining the experience on behalf of the other. But for the voiceless dancer, it is the integration of the whole that is the starting point of the enterprise, and this does not fit the assumption made by others about their practice. For them, this is not about dualism but its imposition onto a practice that demands synthesis. The challenge of explaining it faces both the inadequacy of words and their pointlessness. It also leads to satisfaction with the sensual only as imagined in the confines of the intellect, something Foucault's career surely exemplifies in a desire to subvert and transgress that chiefly values subversion as political action and thus required. The sensuality that might be encountered in the process is hardly considered an end in itself, or where it is, is only proof of the triumph of conventionality.

If I am right, then philosophy-based enquiry into dance is the wrong place to start. This has distracted and detracted from improving our appreciation of how the body is integrated into the mechanism; indeed, that it is the mechanism itself. As someone might have reminded Descartes about the body, he should try formulating a concept without one. Dance, because it attracts so much attention, can tell us much more about ourselves if we avoid resorting to the use of such unsuitable tools. Surely Vico's identification of the limits of the intellect and the effect of its imposition into fields in where it is largely redundant offer an alternative as well as a warning. How is it possible to arrogate to the mind such supremacy on the basis of a limited concept and an even more limited experience? The locus of knowledge of dance is found in the doing of it, and that is exactly what we 
need to do. A project like this one, where so many resonances, personal and professional, are located for its participants and unsparingly presented to its audience, has shown me that if nothing else.

\section{References}

Adair, C. (1992), Women and Dance: Sylphs and Sirens, London: Macmillan.

Adorno, T. (2010), Aesthetics and Politics, London and New York: Verso.

Askay, R. (1999), 'Heidegger, the body and the French philosophers', Continental Philosophy Review, 32 (1),

pp. 29-35, https://www.scribd.com/document/153716163/Askay-Heidegger-The-Body-And-the-French-

Philosophers-Merleau-Ponty. Accessed 06/02/2018

Banes, S. (2013), Dancing Women, London: Routledge.

Berlin, I. (2013), Against the Current, Princeton and Oxford: Princeton University Press.

Croce, B. (1913), The Philosophy of Giambattista Vico, New York: Russell \& Russell.

Descartes, R. (2003), Meditations and Other Metaphysical Writings, London: Penguin Books.

Foster, S. L. (ed.) (1995), Choreographing History, Bloomington and Indianapolis: Indiana University Press. (1996), Dancing Knowledge, Culture and Power, London: Routledge.

Garber, D. (2001), Descartes Embodied, Cambridge: Cambridge University Press.

Heidegger, M. (1982), Parmenides, Frankfurt am Main: Klosterman.

(2011), Basic Writings, London and New York: Routledge. 
Kozel, S. (2007), Closer: Performance, Technologies, Phenomenology, Cambridge, MA: MIT Press.

Merleau-Ponty, M. (1962), The Phenomenology of Perception, London: Routledge and Kegan Paul.

Vico, G. (2000), De nostri temporis studiorum ratione di Giambattista Vico, Firenze: L.S. Olschki.

Williams, B. (1978), Descartes: The Project of Pure Enquiry, London: Penguin Books.

Sporton, G. ([1986] 2017), Double Take, performed by Gregory Sporton and Sandra Norman, The Crit Pit, University of Greenwich, London, UK, 26 April; first performed, New Zealand for Footnote Dance Company, Wellington, February.

Sporton, G. and Norman, S. (2017), Double Take, Vimeo, https://vimeo.com/223043979. Accessed 10 October 2017.

\section{Contributor details}

Gregory Sporton is Professor of digital creativity at the University of Greenwich, London, UK. He originally trained as a dancer at the Victorian College of the Arts in Melbourne, Australia, and had a performing career that included working in New Zealand, the United Kingdom and the Netherlands. He is the author of the book Digital Creativity (London: Palgrave Macmillan, 2015), that gives an account of developing wearable technologies for performance contexts amongst other things. 